\title{
Liderando establecimientos escolares en tiempos de pandemia: algunas certezas entre las incertezas
}

\section{Leading educational establishments in pandemic times: some certainties among the uncertainties.}

\author{
Liderando instituições educacionais em tempos de pandemia: \\ Algumas certezas entre as incertezas.
}

\author{
Felipe Aravena-Castillo \\ Pontificia Universidad Católica de Valparaíso \\ Valparaíso, Chile \\ felipe.aravena@pucv.cl \\ (D) https://orcid.org/0000-0002-9142-8349
}

Recibido - Received - Recebido: 22/11/2020 Aceptado - Accepted - Aprovado: 30/11/2020

DOI: https://doi.org/10.22458/ie.v22i33.3344

URL: https://revistas.uned.ac.cr/index.php/innovaciones/article/view/3344

\begin{abstract}
Resumen: En medio de la incertidumbre provocada por la pandemia experimentada en el año 2020, los directores han tenido que liderar sus escuelas. Pese a ello se plantean ciertas certezas sobre el liderazgo en tiempos turbulentos. Entre ellas se cuentan; la relevancia de comprender la naturaleza cambiante del contexto, la adaptabilidad del líder; el fomento de las prácticas de liderazgo distribuido, desarrollar la flexibilidad y cuidar el bienestar socioemocional personal y de la comunidad.
\end{abstract}

Palabras claves: Liderazgo; Pandemia; Directores, Adminsitración de la Educación, COVID-19.

\begin{abstract}
Amidst the uncertainty created by the pandemics in 2020, schools' headteachers have had to continue leading their schools. Despite this, some certainties about leadership in troubling times emerged. Among them: the relevance of understanding the nature of inconstant contexts, leaders' adaptability; promoting distributed leadership practices, developing flexibility, and caring about both the staff and community's welfare.
\end{abstract}

Keywords: leadership, pandemics, headteachers, school administration, educational administration.

Resumo: Em meio à incerteza causada pela pandemia vivida no ano 2020, os diretores tiveram que liderar suas escolas. No entanto, há certezas sobre a liderança em tempos turbulentos. Estes incluem a importância de compreender a natureza mutável do contexto, a adaptabilidade do líder, incentivando práticas de liderança distribuídas, desenvolvendo flexibilidade e cuidando do bem-estar social-emocional pessoal e comunitário.

Palavras-chaves: Liderança; pandemia, diretores, administração da educação. 
Existe acuerdo en indicar que el contexto influye en el comportamiento de quienes lideran centros escolares, especialmente en cómo gestionan sus escuelas, establecen prioridades y destinan tiempo y energía ante múltiples tareas (Goldring et al., 2008; Clarke \& O'Donoghue, 2016; Hallinger, 2018). Así, la relación entre contexto y liderazgo se presenta en la actualidad como una combinación visiblemente indisoluble. En un año 2020 convulsionado por la pandemia, claramente los factores contextuales en la función directiva toman más fuerza que nunca. Lo anterior, porque el contexto global cambió la dinámica de organización de las escuelas en su esencia cotidiana y en consecuencia las prioridades de los directores.

En particular, en nuestra América Latina, desde el mes de marzo, las escuelas se cerraron presencialmente dando paso a una modalidad de enseñanza y aprendizaje remoto. En un territorio desigual y altamente segregado socioeconómicamente como el de los países latinoamericanos, el primer desafío para los líderes fue pensar en cómo gestionar y liderar una escuela a distancia sin poseer todos los recursos económicos, personales y de conexión para hacerlo. Los directores escolares sumergidos en un nuevo contexto, nunca antes visto, exploraron de manera individual y colectiva, con orientaciones generales de la política pública, algunas potenciales respuestas para abordar el desafío. En un comienzo, las respuestas fueron improvisadas, desorganizadas y temerosas. Ya habiendo pasado más de ocho meses con las escuelas cerradas presencialmente, pareciera ser que se pueden extraer ciertas certezas dentro de la incertidumbre que está generando la pandemia en la forma de pensar y liderar una organización escolar. En razón de esto último, el presente documento expone cinco certezas que la pandemia nos ha recordado que son clave en los líderes escolares.

Una primera certeza observada es que indudablemente el contexto es cambiante. Y así como el contexto es dinámico, las prácticas de liderazgo requieren hacer frente de manera pertinente a las múltiples necesidades que se presentan. De forma que una habilidad clave que requieren desarrollar los líderes escolares es poder leer el contexto en el que se desempeñan e identificar las necesidades de desarrollo de sus actores. Es decir, poseer herramientas para analizar y observar de manera integrada una realidad compleja y altamente dinámica. Aprender a leer los factores contextuales que inhiben o favorecen la mejora escolar es una tarea crítica para los líderes escolares.

Una segunda certeza se refiere a la capacidad para convertirse en un líder adaptativo. Si los líderes no logran adaptarse a los desafíos que proponen los nuevos entornos difícilmente podrán dar respuestas efectivas. Adaptarse a un nuevo medio de enseñanza remota implica rediseñar la organización desde los aspectos simples hasta los más complejos. Por ejemplo; reorganizar las jornadas y horarios de trabajo docente, desarrollar relaciones positivas al interior de la comunidad, mantener la energía, la motivación y la productividad en el trabajo, hasta reflexionar sobre cómo dar respuestas a las necesidades de aprendizaje académico y socioemocional de estudiantes con escaso apoyo y compromiso familiar. Un líder que no logra adaptarse a las circunstancias dinámicas del contexto corre peligro.

Una tercera certeza implica confirmar que las respuestas individuales a problemas complejos no sirven. Afortunadamente, los líderes que concentran poder y autoridad han quedado atrás. La figura de un director escolar que toma decisiones solo, sin consultar a otros, diezma las posibilidades de desarrollar capacidades en su equipo, de abrir espacios de conversaciones productivas y de comprometer a su personal con un desafío de mayor envergadura. En lo concreto, no se espera que los líderes piensen solos desde su casa, en medio de la cuarentena, cómo abordar los múltiples desafíos. Hoy más que nunca es necesario que los líderes involucren de manera directa a distintas voces en buscar respuestas colectivas a problemas colectivos. Un líder capaz de convocar y construir diálogos para aportar con soluciones a problemas 
complejos y profundos como los propuestos por la pandemia tiene más posibilidades de resultar exitoso en la tarea. Por eso, apostar por un liderazgo más distribuido pareciera ser al menos lógico.

Ser flexible en un contexto de cambio profundo se presenta como una cuarta certeza. Adaptarse a un nuevo ambiente invita a practicar la flexibilidad. En otras palabras, significa una oportunidad para no tener miedo a retroceder en decisiones, o avanzar más lento de lo esperado. Un ejemplo claro de la flexibilidad se asocia a tener que balancear los quehaceres domésticos y la vida familiar con las responsabilidades profesionales. Es decir, mantener conversaciones profesionales sobre el aprendizaje de los estudiantes mientras luego tenemos que ir a comprar los productos para preparar el almuerzo, lo cual provoca que la agenda personal de los docentes y directivos muchas veces sea remecida por asuntos familiares y domésticos. Antes de la pandemia, esta realidad era menos común, lo que hacía menos flexibles a los líderes. En cambio, en el contexto actual, comprender y empatizar con las distintas condiciones de trabajo en que se desenvuelven los docentes pareciera ser una clave de la flexibilidad. Un líder flexible es necesario para un tiempo caótico como el propuesto por la pandemia.

Finalmente, y como quinta certeza, la pandemia nos ha dejado de manifiesto que el bienestar emocional de los integrantes de la comunidad importa, y mucho. Harris y Jones (2020) indican que probablemente uno de los efectos más graves de la pandemia, incluso más que el propio virus, ha sido el impacto negativo en la salud mental de los profesores, directivos, familias y estudiantes. Incluso podría no dimensionarse lo que significa para los estudiantes perder el contacto con otros compañeros de clase o, en el caso de los profesores, verse imposibilitados de mantener una conversación profesional con un colega mientras se comparte un café. Para que un líder pueda ayudar a otros a desarrollarse emocionalmente necesita estar bien. Para ello, se requiere practicar el autocuidado, la conciencia de sí mismo y el optimismo. De ahí que un recordatorio crucial para los líderes es que las emociones propias y de los actores que pertenecen a la comunidad requieren ser gestionadas; por tanto, gestionar los procesos pedagógicos así como mantener relaciones positivas entre los miembros del establecimiento escolar es igualmente importante.

Un líder escolar caminando por una ruta incierta como la propuesta por la pandemia requiere mirarse a sí mismo y reflexionar ¿qué he aprendido en esta crisis?, ¿por qué estoy aprendiendo esto?, ¿qué dice ese aprendizaje de mí?, ¿qué tipo de líder estoy siendo y qué líder quiero ser? La pandemia ha traído múltiples incertidumbres que cambiaron las prácticas, prioridades y tipos de tareas que los líderes deben afrontar. Probablemente, algunas de estas certezas serán irreversibles y harán pensar a los diseñadores de la política pública y los programas de formación profesional en cómo desarrollar capacidades en los líderes para gestionar cambios en contextos turbulentos.

\section{REFERENCIAS}

Clarke, S. \& O'Donoghue, T. (2016). Educational leadership and context: A rendering of an inseparable relationship. British Journal of Educational Studies, 1-16. DOI 10.1080/00071005.2016.1199772

Goldring, E., Huff, J., May, H. \& E. Camburn, E. (2008). School Context and Individual Characteristics: What Influences Principal Practice? Journal of Educational Administration 46, (3): 332-352. Recuperado de https://eric.ed.gov/?id=EJ796588

Hallinger, P. (2018). Bringing Context out of the Shadows of Leadership. Educational Management Administration and Leadership, 46(1): 5-24. DOI 10.1177/1741143216670652

Harris, J. \& Jones, M. (2020). COVID 19 - school leadership in disruptive times. School Leadership \& Management, 40:4, 243-247. DOI: 10.1080/13632434.2020.1811479 